\title{
Automatic Control of Center Pivot Irrigation System
}

\author{
Osman Ahmed Said Ahmed Mohamed ${ }^{1}$, Dalia Mahmoud ${ }^{2}$ \\ ${ }^{1}$ Deparment of Control, Faculty of Engineering, Al-Neelain University, Sudan \\ ${ }^{2}$ Assosciate Professor, Head of Deparment of Control, Faculty of Engineering, Al-Neelain University, Sudan
}

\begin{abstract}
This paper discuss how to control of center pivot irrigation system automatically without present of human in the field. Microcontroller considerd the important component in this project received Signals from temperature and humidity sensors then signals transmitted to motor even to moving sprinklers forward and reverse even irrigated to field using pump to raise the water to the top of tower and distributed by using water spray. Pc interface by using max232 and Rs232. This system to allow montoring to field from far.
\end{abstract}

Keywords: Stepper motor, PIC microcontroller , C Programing, Serial communction , lab view

\section{Introduction}

Irrigation is the artificial processing of water to the land or soil. It is used to aid the growth of agricultural crops, maintenance of landscapes, and revegetation of disturbed soils in dry areas and during periods of irregular rainfall. Also, irrigation also has other uses in crop production, which include protecting plants from frost, preventing weed growing in grain fields and aiding in preventing soil consolidation. Vice versa, agriculture that dependss only on direct rainfall is described as rain-fed or dryland farming. Irrigation systems are also used for dust suppression, disposal of sewage, and in mining. Irrigation is often studied together with drainage, which is the natural or artificial removal of surface and sub-surface water from a given area [1].Different types of irrigation procedures differ in how the water collected from the source is distributed within the field. In general, the aim is to support the entire field uniformly with water, so that each plant has the amount of water it requires, neither too much nor too little. The recent methods are effective enough to achieve this goal.In this research center pivot method has been chosen because it can reduce high initial cost to be spent by the farmer. Also the maintenance cost of the machine could be cashing for the farmers. This can be compensated with the larger productivity of crops. The main advantage of the center pivot irrigation system is that it can be used to irrigate long distance with only limitation that surface topography should be flat.

\subsection{Problem Statement}

In many irrigation projects there are some issues that includes difficulty of guiding the amount of water and organized in vast areas, frequent labor in large spaces, difficulty unequal irrigation that causes high cost. To solve these problems, automated irrigation systems must be introduced. In this paper a center pivot procedure was aimed to solve the problems involved in irrigation systems.

\subsection{Objectives}

The main objectives are:

- To solve the problem of controlling the amount of water in the field under study.

- To automate the irrigation system using PIC16F877A.

- To ensure the suitable irrigation for the all field areas.
- To practice the Proteus, Lab View and Micro C programs for the simulation and building the code required in the project.

\subsection{Methodology}

In this paper the following procedures and steps were taken:

- Building simulation program using proteus application.

- Using Micro C software program to build a code and to deal in.

- Buliding hardware design

\section{Hardware Tools}

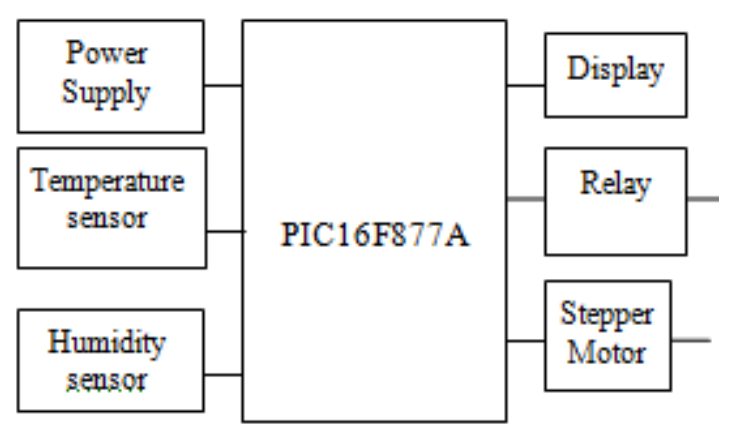

Figure 1: Block diagram of automatic center pivot irrigation

\subsection{Microcontroller PIC16F877A}

The PIC16F877A is a low-power, high-performance CMOS 8-bit microcontroller with $8 \mathrm{~K}$ bytes of in-system programmable flash memory. The device is designed using Atmel's high-density nonvolatile memory technology and it's compatible with the industry-standard 80C51 instruction set. The on-chip Flash permits the memory to be reprogrammed in-system or by a conventional nonvolatile memory programmer. By joining a versatile 8-bit CPU with in-system programmable Flash on a monolithic chip, the PIC16F877A is a powerful microcontroller that supplies a highly-flexible and cost effective solution to a lot of embedded control applications. The PIC16F877Aserves the following standard features: $8 \mathrm{~K}$ bytes of Flash, 256 bytes of RAM, 32 I/O lines, Watchdog timer, two data pointers, three 16-bit timer/counters, a six-vector two-level interrupt architecture, a full duplex serial port, on-chip oscillator, and clock circuitry. Also, the PIC16F877A is built with static logic for operation down to zero frequency and supports two 


\section{International Journal of Science and Research (IJSR) \\ ISSN (Online): 2319-7064 \\ Index Copernicus Value (2013): 6.14 | Impact Factor (2015): 6.391}

software selectable power saving modes. The Idle Mode stops the CPU while permitting the RAM, timer/counters, serial port, and interrupt system to continue functioning. The Power-down mode saves the RAM data but freezes the oscillator, disabling all other chip functions until the next interrupt or hardware reset. The microcontroller is the heart of the circuit. It leads all the functions. It interfaces the RTC serially and retrieves the time and day from it. Any input using the keypad is read by the microcontroller and following actions are done. The microcontroller sends the real time, alarm which is as well as the day to the display unit. When the real time and alarm time becomes equal, the alarm unit is triggered by the controller. Moreover, the alarm timings are stored in theinternal EEPROM of the microcontroller. The pindiagram is given in the fig. 2

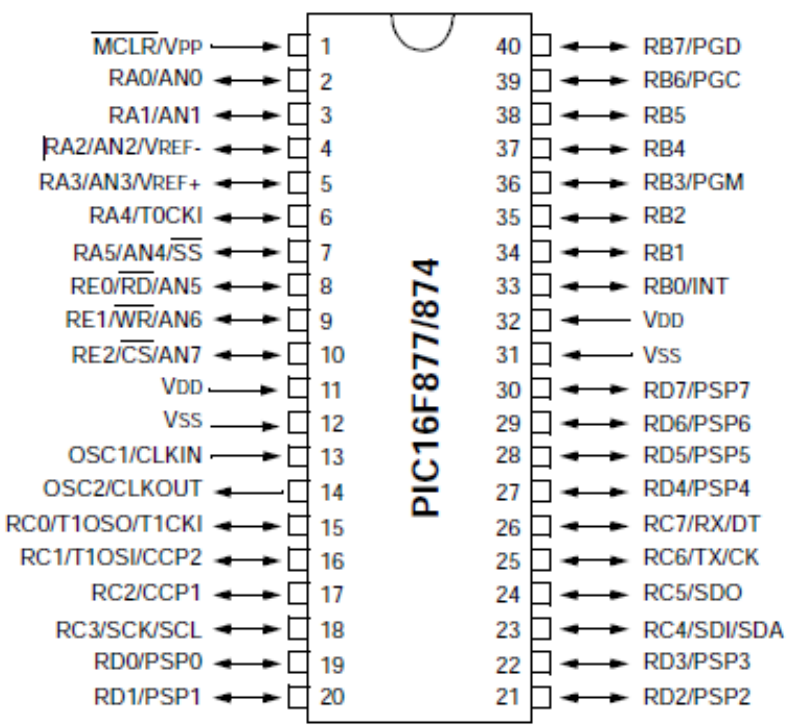

Figure 2: Pin diagram of PIC16F877A

\subsection{LM-35 Temperature Sensor}

The LM35 series, shown in Figure 14.2 are precision integrated-circuit temperature sensors, whose output voltage is linearly proportional to the Celsius (Centigrade) temperature. The LM35 and it has an advantage over linear temperature sensors calibrated in ${ }^{\circ}$ Kelvin, as the user doesn't have to subtract a large constant voltage from its output to obtain convenient Centigrade scaling. The LM35 does not require any other calibration or trimming to provide similar accuracies of $\pm 1 / 4^{\circ} \mathrm{C}$ at room temperature and $\pm 3 / 4^{\circ} \mathrm{C}$ over a full -55 to $+150^{\circ} \mathrm{C}$ temperature range. Low cost is insured by trimming and calibration at the wafer level

The LM35's low output impedance, linear output, and precise inherent calibration make interfacing to readout or control circuitry especially easy. It can be used with single power supplies, or with plus and minus supplies. As it makes only $60 \mu \mathrm{A}$ from its supply, it has very low selfheating, less than $0.1^{\circ} \mathrm{C}$ in still air .

The LM35 is aimed to operate over a $-55^{\circ}$ to $+150^{\circ} \mathrm{C}$ temperature range as shown in Figure 14.2. LM-35 Pinout, while the $\mathrm{LM} 35 \mathrm{C}$ is desined for a $-40^{\circ}$ to $+110^{\circ} \mathrm{C}$ range $\left(-10^{\circ}\right.$ with higher accuracy). The LM35 series is available packaged in hermetic TO-46 transistor packages, while the
LM35C, LM35CA, and LM35D are also available in the plastic TO-92 transistor package. The LM35D is also available in an 8-lead surface mount small outline package and a plastic TO-220 package [11].

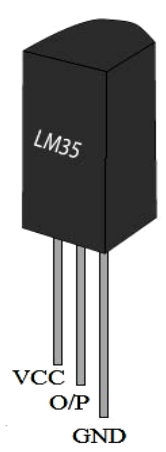

Figure 3: LM-35 Pin out

\subsection{Stepper Motor}

A stepper motor (or step motor) is a brushless DC electric motor. It divides a full rotation into a sequence of steps. Motor's position can be used to move and hold at one of these steps without any feedback sens. Switched are very large stepping motors with a low pole count, and generally are closed-loop commutated. DC brush motors rotate always when voltage is applied to their terminals. Stepper motors, also, effectively have many "toothed" electromagnets distributed around a central gear-shaped piece of iron. The electromagnets are energized by an external control circuit.[2].

\subsection{Power Supply Unit}

A power supply of $+12 \mathrm{Vand}+5 \mathrm{~V}$ is needed for circuit operation. A supply of $+12 \mathrm{~V}$ is needed by the relay. $+5 \mathrm{~V}$, supply is required by the microcontroller, RTC and the pullup resistors. A step-down transformer of $12 \mathrm{~V}$ rating and Power regulator IC LM7805 is used. The AC mains power supply of $230 \mathrm{~V}, 50 \mathrm{~Hz}$ is step-down using the transformer to $+12 \mathrm{~V}$. A bridge rectifier circuit using diodes is connected at the secondary of the transformer.

\subsubsection{Voltage Regulator}

Voltage regulator ICs7805 are present with fixed (typically 5,12 and $15 \mathrm{~V}$ ) or variable output voltages. The maximum current it can pass also rates them. Negative voltage regulators are available, mainly for use in dual supplies. Most regulators include some automatic protection from over current (overload protection) and overheating (thermal protection). A lot of fixed voltage regulator ICs has 3 leads. They have a hole for fixing a heat sink if necessary.

\subsection{Display Unit}

This is the first interfacing model for the Parallel Port. This model doesn't use the Bi-directional form that found on newer ports, thus it should work with most, if not, all Parallel Ports. It however doesn't show the use of the Status Port as an input. These LCD Modules are very available these days, and are quite simple to process with, as all the 


\section{International Journal of Science and Research (IJSR) \\ ISSN (Online): 2319-7064}

Index Copernicus Value (2013): 6.14 | Impact Factor (2015): 6.391

logic needed to run them is on board. The LCD panel's Enable and register select is connected to the Control Port. The Control Port is an open collector / open drain output. While most Parallel Ports have Internal pull-up resistors, there are a few which don't. So we can add external pull resistors which makes the circuit more portable. Therefore by operating the two $10 \mathrm{~K}$ external pull up resistors, the circuit is more portable for a wider range of computers, some of them may have no internal pull up resistors. We hard wire the R/W line of the LCD panel, into write mode. This will cause no bus conflicts on the data lines. As a result of that we cannot read back the LCD's internal Busy Flag which shows to us if the LCD has accepted and completed processing the last instruction. This problem is fixed by inserting known delays into the program. The $10 \mathrm{k}$ Potentiometer controls the contrast of the LCD panel. The power supply can be set to $5 \mathrm{v}$ or on onboard +5 regulator. The 2 line $\mathrm{x} 16$ character LCD modules are available with a variety in range of manufacturers.

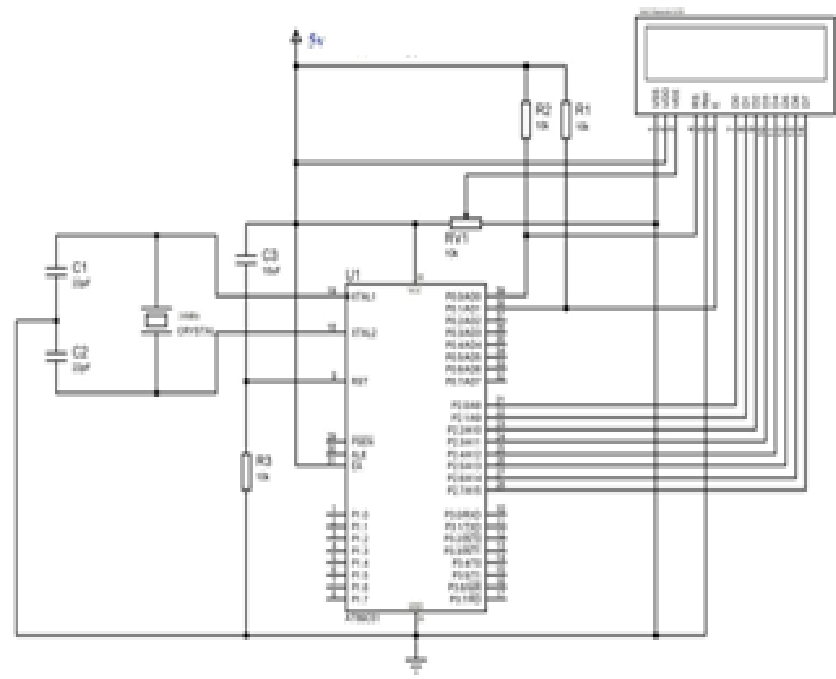

Figure 6: LCD interfacing with the Microcontroller

\subsection{Relay}

Relay is an electro-mechanical device which used to isolate single electrical circuit from the other. It allows a low current control circuit to make or break an electrically isolated high current circuit path. Complete isolation is proceeded by the relay between the triggering source applied to the terminal and the output. This complete isolation is a feature that makes relay different from other integrated circuits and is also important in many digital applications. It is a feature that certain semiconductor switches (e.g. transistors, diodes and integrated circuits) cannot perform. In this circuit a $12 \mathrm{~V}$ magnetic relay is used. In magnetic relay, insulated copper wire coil is used tomagnetize and attract the plunger .The plunger is normally connected to N/C terminal. A spring is connected to attract the plunger upper side. When output is received by relay, the plunger is attracted and the buzzer is on.

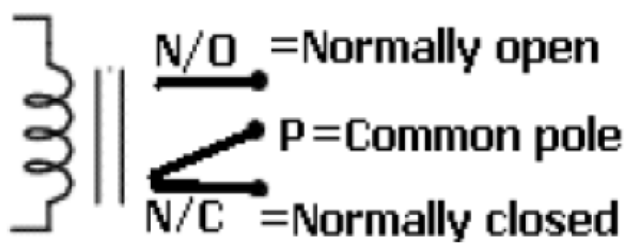

Figure 7: Relay

\section{Methodology}

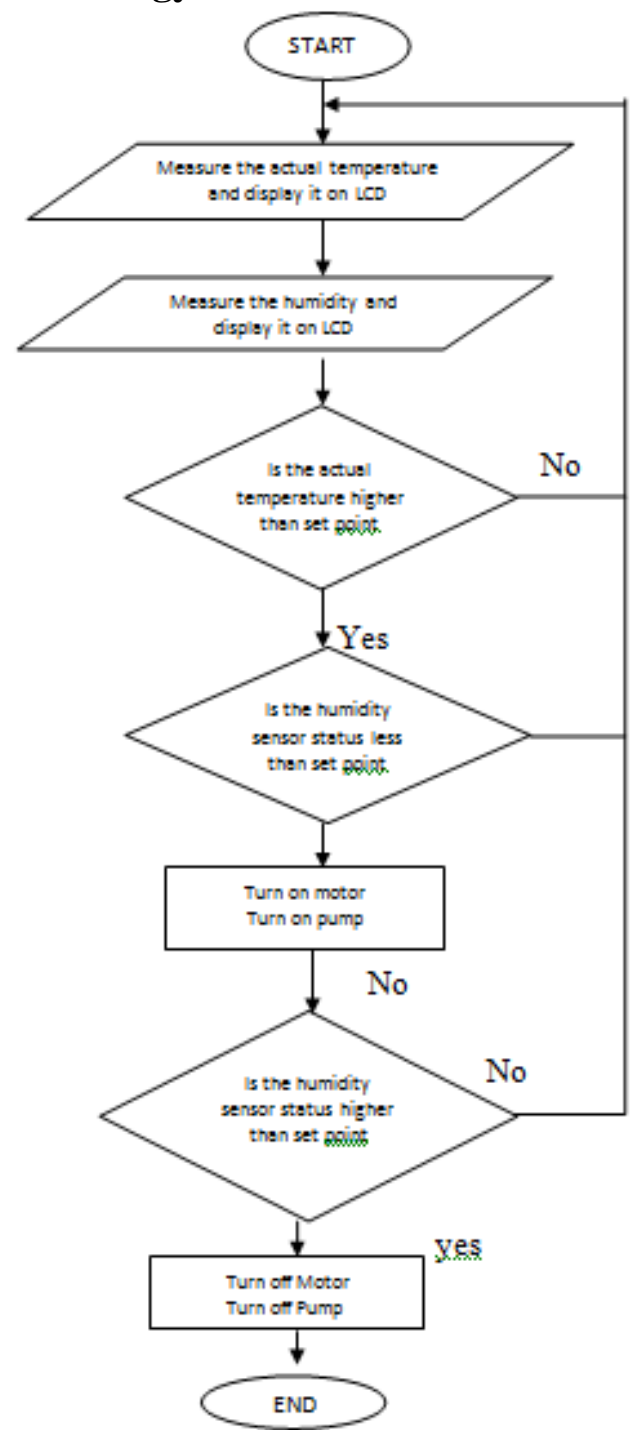

Flow chart of centre pivot irrigation system

The actual temperature will be measured by using LM35 sensor that gives voltage in it is output proportionally to the measured temperature and humidity and feedback to microcontroller. In microcontroller, the error between the desired and the actual temperature and humidity and then send actuator signal to stepper motor and pump. The flow chart showed in Fig3.2 shows the details of process.

When system starts the measured temperature will be display on LCD. The control in the operation of the motor and the pump by comparing the real values of the sensor temperature and humidity values unwanted and was also control the speed of the motor by the rheostat was used LEDs of the motor is working or not and the motor works movement counterproductive or forehand and was also 


\section{International Journal of Science and Research (IJSR) \\ ISSN (Online): 2319-7064}

Index Copernicus Value (2013): 6.14 | Impact Factor (2015): 6.391

controlled by the computer using serial communication using Max232 and Rs232.

Is used to the idea of the soil moisture sensor which is interfaced with microcontrollers and the other part is connected with wires to measure moisture and are placed two wires in the soil so that when the water flows on the soil, Microcontroller checks the output of soil moisture sensor. If the water level is low then microcontroller will on the relay that will switch on the Motor and Water pump. Then when the water level is high it will switch off Motor and the Pump.

\section{Result}

\subsection{Significant Result}

The implementation of this project has result in two ultimate circuits, the one that represents the simulation of the system and discussed in Figure 4.2 and the hardware circuit of the system.

\subsection{Simulation Result}

As shown in Figure 4.1 the simulation result for the system is viewed after the program code was developed and the loaded into the PIC, MCU, commands testing operation was started the illuminating LEDs are indicatory response to the commands.

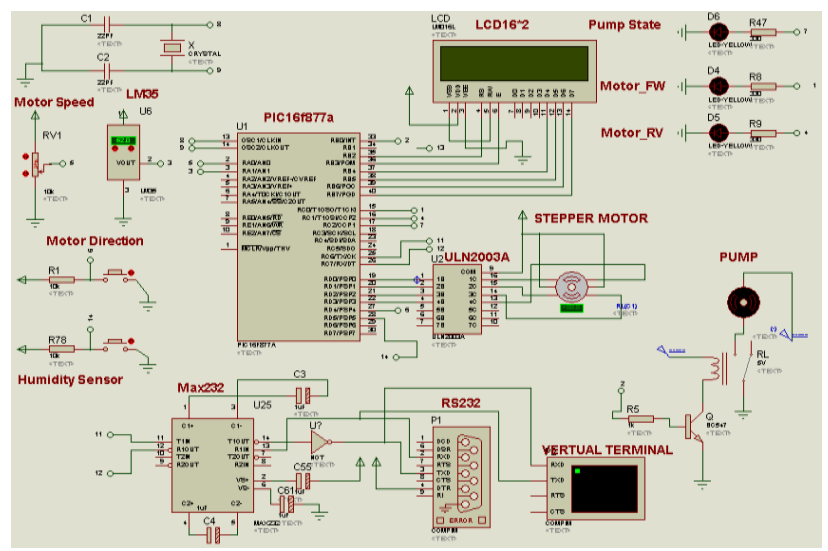

Figure 4.1: Basic Irrigation System Simulation

\subsection{Hardware Result and Discussion}

The temperature control system has been successfully implemented for hardware construction and tests have been carried out after the program loaded into pic microcontroller to verify that the circuit functions correctly and probably as shown in Fig 4.2. This section briefly discusses the result obtained during the project development and simulated test.

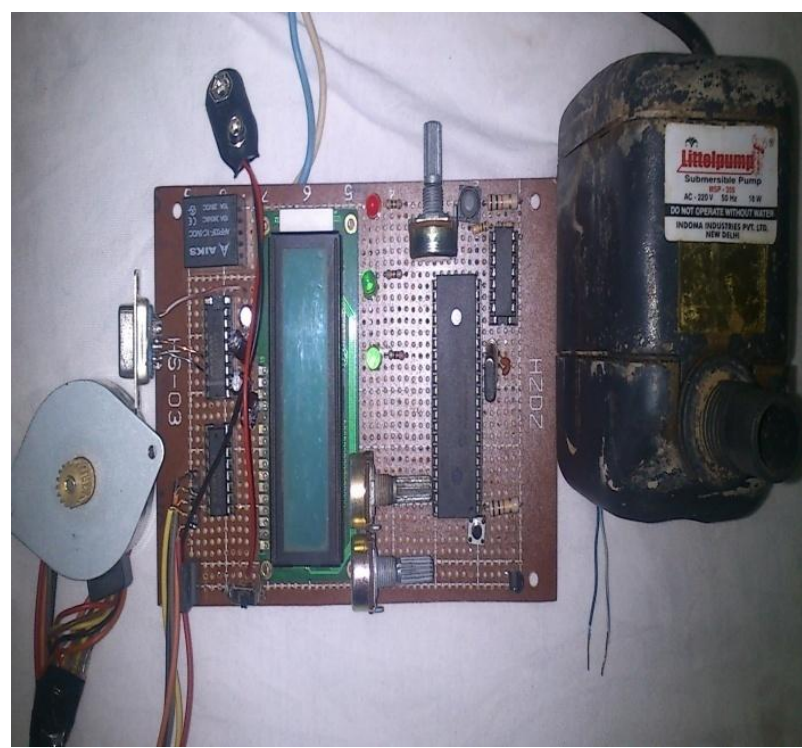

Figure 4.2: Hardware Circuit

\subsubsection{Simulation Part}

The programming has been found to be working successfully. It has been simulated and tested many times at different set point using proteus simulation package and lab view simulation package. In this situation motor direction is forward and the pump is on as the LEDs shown that in Figure 4.3.

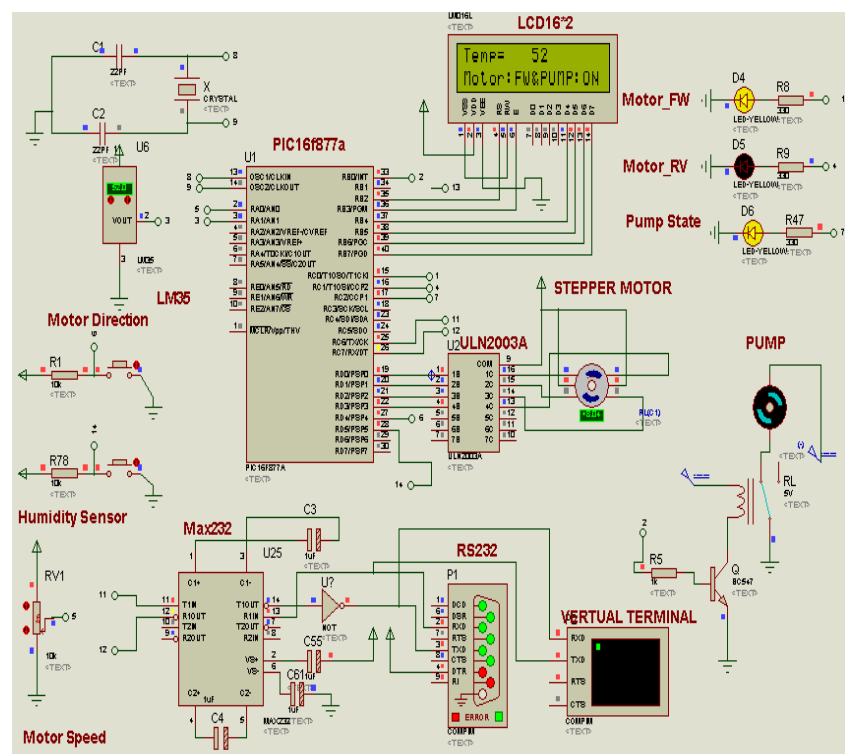

Figure 4.3: Basic Irrigation System Simulation in Forward Direction

In this situation when motor direction switch is pressed the stepper motor changes it is direction to the reverse one as shown in Figure 4.4. 


\section{International Journal of Science and Research (IJSR) \\ ISSN (Online): 2319-7064}

Index Copernicus Value (2013): 6.14 | Impact Factor (2015): 6.391

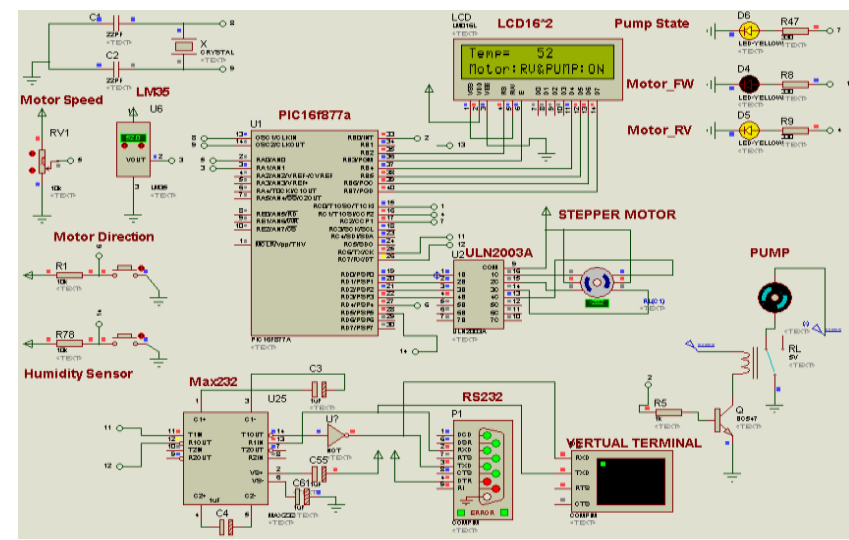

Figure 4.4: Basic Irrigation System Simulation in Reverse Direction

Lab View package is used to monitor the temperature degree and the status of both motor and pump using LEDs. Figure 4.5 represents Lab View Front Panel.

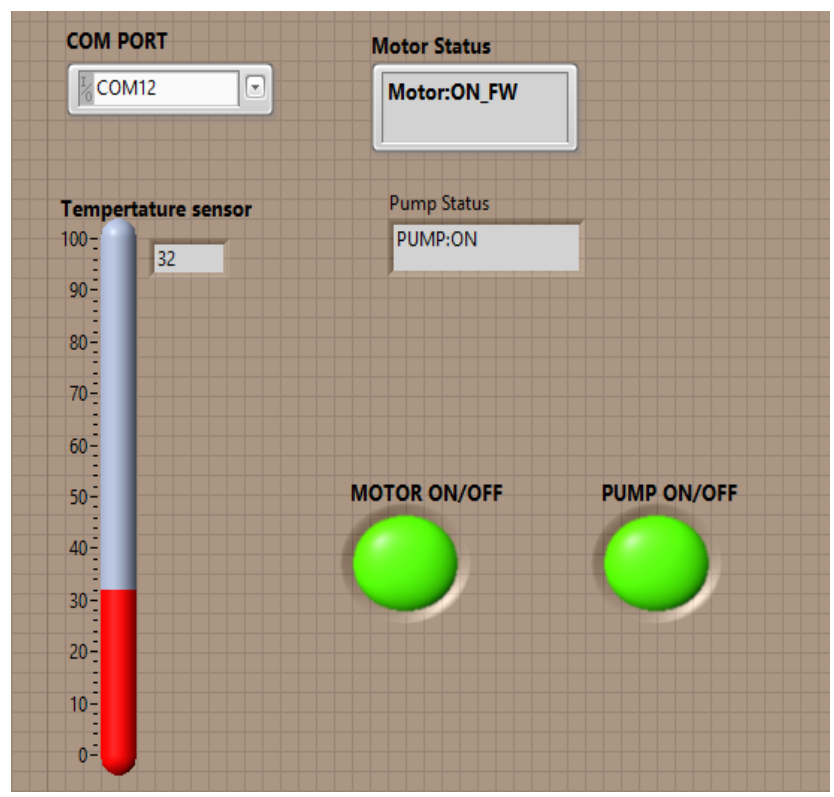

Figure 4.5: Lab View Front Panel

\subsubsection{Hardware Part}

Once the program has been loaded into microcontroller, the overall hardware design has been tested as different temperature degrees and it found work correctly and probably as scheduled as shown in Figure 4.6.

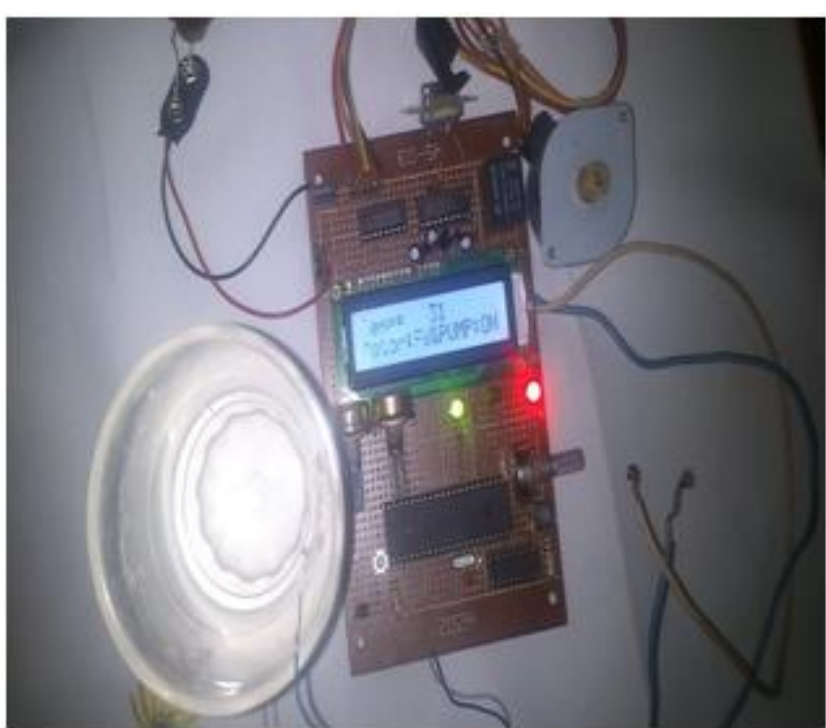

Figure 4.6: Hardware Circuit Testing

\section{Conclusion}

The center pivot irrigation system has been controlled automatically through microcontroller by building a system of two separated parts, the flexible part counts on high level languages and the solid part relies on an electronic and mechanical parts. And then connect the solid part with the graphical part using serial port (Rs232) so as to show the information you needed to know from the field, which is electronically controlled using push buttons and find out the status of each of the motor, pump and the temperature.

\section{Future Recommendation}

1) Using PLC instead of microcontroller.

2) Using wireless communication.

\section{References}

[1] Mader, Shelli (May 25, 2010),"Center pivot irrigation revolutionizes agriculture", The Fence Post Magazine.

[2] http://en.wikipedia.org/wiki/Stepper_motor $1 \& 2$ was on Friday 3/1/2013 19:00 pm

[3] Liptak, Bela G. (2005). Instrument Engineers' Handbook: Process Control and Optimization

[4] http://www.imagesco.com/articles/picstepper/02.html

[5] http://en.wikipedia.org/wiki/Microcontroller

[6] http://www.radioelectronics.com/info/telecommunicatio ns_networks/rs232/eia-rs232-c-d-standards.php

[7] http://en.wikipedia.org/wiki/rs232

[8] www.sherline.com

[9] http://www ian.umces.edu

[10] Texas Instruments, Copyright (C) 2011, Texas Instruments Incorporated

[11]Mason, C. R. "Art \& Science of Protective RelayingChapter 2, GE Consumer \& Electrical". Retrieved October 9, 2011.

[12]Zocholl, Stan, AC Motor Protection. Schweitzer Engineering Laboratories, Inc. (2003). 